\title{
ПСИХОЛОГИЧЕСКАЯ ГОТОВНОСТЬ ВОСПИТАТЕЛЕЙ К ПАРТНЕРСКОЙ ПОЗИЦИИ ПРИ СОЗДАНИИ РАЗВИВАЮЩЕЙ ОБРАЗОВАТЕЛЬНОЙ СРЕДЫ В ДОШКОЛЬНОМ УЧРЕЖДЕНИИ
}

\section{PSYCHOLOGICAL READINESS OF \\ EDUCATORS FOR A PARTNER POSITION IN CREATING A DEVELOPING EDUCATIONAL ENVIRONMENT IN A PRESCHOOL INSTITUTION}

\section{Shibayeva \\ O. Sobakinskikh}

Summary: The purpose of the research presented in the publication was to characterize the readiness of kindergarten teachers to implement a partner position when they jointly plan activities for the development of age-related neoplasms of preschool children. Diagnostic methods for identifying psychological difficulties of educators in solving planning tasks in productive interaction are described, and errors in the implementation of value-target and operational-technical levels of interaction organization are characterized when creating plans for the implementation of educational programs for preschoolers within a week. The results of content analysis of the array of weekly plans of kindergarten teachers are presented, and indicators of the representation of difficulties and errors at each of the levels are given.

The diagnostic results allow us to substantiate the model of organizational and psychological conditions that contribute to the dynamics of psychological readiness of teachers to create a developing educational environment that meets the requirements of Federal state educational standard.

Keywords: kindergarten teachers, psychological readiness, developing educational environment, partnership, operational and technical, value-target component of joint activity, content analysis method, organizational and psychological conditions for changes in psychological readiness.
$\mathrm{B}$ мастоящее время одним из актуальных направлений реализации ФГОС ДО [12] выступает необходимость создания развивающей образовательной среды (OC) для воспитанников, требующая от воспитателей преодоления профессиональных стереотипов проведения регламентированных занятий по формированию у детей дискретных умений и навыков, вовлечениях их в локальные фестивально-праздничные мероприятия. Современный ФГОС ориентирует педагогов ДОУ при планировании на приоритеты возрастно-нормативных достижений дошкольников, что делает необходимым для воспитателей научиться пользоваться при описании

\author{
Шибаева Людмила Васильевна \\ Д.псх.н., профессор, Сургутский государственный \\ педагогический университет \\ shibaeva2003@gmail.com; \\ Собакинских Оксана Владимировна \\ аспирант, Сургутский государственный педагогический \\ университет \\ mixvel@yandex.ru
}

Аннотация: Цель исследования, представленного в публикации, состояла в характеристике готовности воспитателей ДОУ к реализации партнерской позиции при совместном планировании ими деятельности по развитию возрастных новообразований дошкольников. Описаны диагностические приемы выявления психологических затруднений воспитателей при решении задач планирования в продуктивном взаимодействии, дана характеристика ошибок при реализации ценностно-целевого и операционно-технического уровней организации взаимодействий при создании планов реализации развивающих программ для дошкольников в масштабе недели. Представлены результаты контент-анализа массива недельных планов воспитателей ДоУ и приведены показатели затруднений и ошибок на каждом из уровней.

Результаты диагностики позволяют наметить модель организационно-психологических условий, способствующих динамике психологической готовности воспитателей к созданию развивающей образовательной среды, отвечающей требованиям современных ФГОС Д0.

Ключевые слова: воспитатели ДОУ, психологическая готовность, развивающая образовательная среда, партнерство, операционно-технический и ценностно-целевой компонент совместной деятельности, метод контент-анализа, организационно-психологические условия изменения психологической готовности результатов совместной деятельности характеристикой возрастных новообразований и прилагать усилия при организации деятельности детей к созданию ситуаций их формирования. Это предполагает изменение профессионального мышления воспитателей ДОУ, оформления у них новых способов стратегического планирования, ориентировки на партнерство с коллегами по созданию развивающей образовательной среды (РОС).

Проблема исследования, представленного в публикации, состояла в выявлении исходного уровня готовности воспитателей ДОУ к реализации партнерской 
позиции при планировании совместной деятельности развития возрастных новообразований дошкольников.

Исследование проводилось в контексте разработки и последующей апробации модели организационнопсихологических условий, способствующих профессионально-личностному развитию воспитателей, профилактике профессионально-личностных кризисов при их переходе к обновленным способам профессиональной деятельности, ориентированным на ФГОС.

В настоящее время предложены варианты подходов к характеристике образовательных сред $[1,2,3,6,11$, $15,16]$. Среди них большое значение приобретает подход, ориентированный на коммуникативно-ориентированную модель, разрабатываемый В.В. Рубцовым, К.И. Поливановой, И.В. Ермаковой [8, 9]. В ее основе - представление об ОС как форме коммуникативного взаимодействия, создающего особую общность субъектов образования в процессе сотрудничества.

Согласно В.В. Рубцову ОС это сложившаяся «полиструктурнаяя система прямых и косвенных воспитательно-обучающих воздействий, реализующих явно или неявно представленные педагогические ценностные установки педагогов, характеризующие цели, задачи, методы, средства и формы образовательного процесса в данной школе» [9, с 177]. Основные структурные компоненты: направленность на ценности развития учащихся, социально-психологическая структура коллектива, объединенного общими целями, созидательный психологический климат.

В настоящее время приобретает все большее значение «экопсихологический» подход [7]. Он формировался в рамках психо-дидактической парадигмы развивающего образования. Согласно данному подходу, педагогические и психологические условия создаются для раскрытия проявившихся и потенциальных способностей обучаемых на основе требований возрастной социализации и задатков. Развивая данный подход, В.И. Панов определяет ОС как динамическое образование, системный продукт взаимодействия участников [7]. Среди основных принципов реализации такого подхода важным является ориентация создаваемых условий на соответствие возрастным этапам развития детей, включение их в различные виды совместной деятельности, актуализация зоны ближайшего развития с одновременной опорой на развитие актуального уровня способностей.

В.И. Панов, выделяя три основных компонента - деятельностный (технологический), коммуникативный и пространственно-предметный, описывает следующие организационно-психологические условия, необходимые для их формирования:
- развитие интересов и способностей посредством включения в разнообразные виды деятельности;

- уход от репродуктивных форм педагогической деятельности - передачи знаний, умений и навыков - к продуктивным. К подобным формам относят сотрудничество субъектов в процессе коллективно-распределенной деятельности;

- формирование рефлексивной позиции педагогов, поощряя развитие способности «анализировать себя со стороны [7].

При характеристике взаимодействия участников, создающих развивающие ОС, подчеркивается значимость ценностно-смысловой синхронизации деятельности. Так В.И. Слободчиковым педагогическое сообщество характеризуется как психологически особая со-бытийная общность [11]. Подчеркивается то, что развивающая образовательная среда возникает с началом взаимодействий педагогов - в их совместной деятельности, ориентированной на ценности развития участников. Ценностное единение участников придает ситуациям взаимодействий статус со-бытийности $[10,11]$.

В русле данного подхода весьма актуальной становится проблема исследования того, как преодолеваются психологические затруднения при переходе воспитателей дОУ от ориентировки на индивидуальную работу по созданию строго регламентирующих деятельность детей программ организации занятий в течение дня, недели, месяца - к ценностно-смысловой консолидации деятельности на основе стратегии и тактики взаимодействия по сопровождению возрастных новообразований детей.

Это направление предполагает овладение воспитателями позиции партнерства в условиях продуктивного взаимодействия с коллегами, создающими развивающее образовательное пространство на основе соучастия в целевых программах, ориентированных на становление возрастных новообразований воспитанников.

В исследованиях Л.В. Шибаевой подчеркивается значение адресных целевых программ, объединяющих педагогов при создании РОС школы [14]. Автором прямо соотносится развивающий потенциал образовательной среды с готовностью педагогов выступать лидерами и участниками масштабными развивающих программ, которые объединяли бы комплекс учебно-воспитательных ситуаций, ориентированных на интегративные психические новообразования учеников и служили бы объединению усилий педагогов по достижению совместных развивающих результатов [14].

Необходимо подчеркнуть недостаточность исследований развивающих образовательных сред как продук- 
тов совместной продуктивной деятельности участников дошкольных образовательных учреждений, ориентирующихся на ценности развития возрастных новообразований дошкольников.

В процессе становления воспитателей в позиции участников создания РОС при характеристике ценностно-целевого компонента собственной деятельности необходима ориентация на психологические закономерности развития детей, технологии и методы проектирования целевых программ, опосредованных приоритетом ценностей развития ведущих новообразований в дошкольном детстве. В этом отношении большое значение приобретает овладение способами стратегического и тактического взаимодействия с партнерами, актуализации рефлексивного компонента при анализе затруднений в столь приоритетных профессиональных задачах. Теоретическими основаниями для характеристики динамики готовности воспитателей ДОУ к высоким уровням реализации профессионального взаимодействия в нашем исследовании выступили положения деятельностного подхода $[4,5,13]$. Они позволяют выделить такие компоненты в реализации совместной деятельности как ценностно-смысловой и операционно-технический [4]. Достижение согласованности этих компонентов в партнерском взаимодействии и рассматривалось как достижение наиболее высоких уровней совместной продуктивной деятельности [5].

Объектом исследования выступало профессиональное развитие воспитателей ДОУ как участников совместной деятельности по созданию развивающей образовательной среды.

Предмет исследования - психологическая готовность педагогов к партнерству при планировании профессиональной деятельности по сопровождению возрастно-нормативных достижений дошкольников

Исследование включало осуществление диагностики психологической готовности воспитателей к планированию совместной развивающей деятельности в группе детского сада. В состав экспериментально группы (ЭГ1) вошли 22 воспитателя ДОУ №20 и 22 воспитателя контрольной группы (ЭГ2) ДОУ №26 г. Сургута. Для первичной диагностики был выбран такой масштаб реализации профессиональной деятельности как неделя и такой этап профессиональной деятельности как ее планирование. В качестве эмпирического материала выступали тексты 44 планов в ЭГ1 и 44 планов в ЭГ2.

Для выявления готовности педагогов к партнерству при планировании профессиональной деятельности как совместной необходимо было разработать шкалу оценки качества планов и отражения в них всех компонентов, характеризующих направленность на взаимодействие при достижении развивающих результатов работы с дошкольниками.

Реализовалось два направления диагностики готовности воспитателей быть участниками создания развивающей образовательной среды ДОУ:

1. ориентировка на стратегические программы работы с детьми для обеспечения возрастно-нормативных достижений;

2. согласованность у воспитателей, работающих в одной группе детей, ценностно-смысловых ориентаций на достижение ведущих психических новообразований дошкольников, которая выражалась бы критериях удовлетворенности собственной деятельностью, выявляемых в процессе рефлексии достижений и неудач.

В первом направлении исследования в качестве основного метода изучения готовности воспитателей к реализации взаимодействия на операционно-техническом уровне выступал метод анализа продуктов деятельности - текстов планов работы в группе на неделю. В качестве метода, который позволял бы выявить готовность воспитателей к реализации продуктивного взаимодействия на ценностно-смысловом уровне деятельности, выступал метод контент-анализа результатов рефлексивной беседы.

Диагностические приемы должны были позволить выявлять затруднения и дифференцировать ошибки воспитателей в достижении качества планов, описывающих программы развития психических новообразований дошкольников в соответствующих возрасту видах и формах деятельности.

При реализации контент-анализа текстов планов были использованы следующие индикаторы, характеризующие оптимальный вариант тех условий, которые могли бы свидетельствовать об ориентировке воспитателей на развивающие результаты:

1. Ориентация на достижение динамики возрастнонормативных показателей развития детей. Это должно было находить выражение в формулировке целей и задач. От описания целей на языке частных умений, знаний и навыков детей воспитатели должны были переходить к описанию на языке возрастно-нормативных достижений.

2. Обеспечение единства замысла и преемственности запланированных мероприятий, средств, способов в контексте темы недели и итогового результата деятельности (культурно-образовательного события).

3. Установление соответствия форм и содержания деятельности возрастным характеристикам вос- 
питанников.

Критерии оценки качества продукта совместной деятельности при создании плана образовательной работы на неделю с воспитанниками представлены в таблице 1 Приложения 1.

Анализ того, насколько оказывались воспитатели готовы руководствоваться согласованными ценностно-целевыми ориентирами при планировании деятельности с партнером, осуществлялся на основе контент-анализа рефлексивной беседы с воспитателями (Приложение 2).

В качестве индикаторов оценки проявления готовности воспитателей ориентироваться во взаимодействии с партнером на развивающие цели и готовности осуществлять их в партнерстве выступали критерии, представленные в таблице 2 и Приложения 2. К таким индикаторам были отнесены такие эмпирические показатели как умение описать эталон продукта совместной деятельности, адекватно соотнести эталонный продукт с тем, который был получен в процессе взаимодействия с партнером.

К индикаторам, свидетельствующим о готовности к партнерству, относились рефлексивные высказывания о ценностях и целях возрастного развития детей как результатах совместной с партнером деятельности, о качестве собственных действий в позиции партнера, оценке партнера как участника совместной программы.

Проведенная диагностика позволила выявить долю воспитателей в двух детских садах с разным уровнем психологической готовности к реализации партнерской позиции при решении таких профессиональных задач как планирование деятельности в масштабе недели, ориентированной на возрастно-нормативные достижения дошкольников. Обобщенные результаты представлены в таблице 1.

Доля педагогов ДОУ с разным уровнем готовности к партнерству при создании развивающих программ деятельности с воспитанниками

Таблица 1

\begin{tabular}{|l|c|c|c|c|}
\hline Показатель & & Низкий & Средний & Высокий \\
\hline Уровень качества про- & $Э Г 1$ & $72,7 \%$ & $18,2 \%$ & $9,1 \%$ \\
\cline { 2 - 5 } $\begin{array}{l}\text { дукта совместной дея- } \\
\text { тельности (план работы } \\
\text { на неделю) }\end{array}$ & $Э Г 2$ & $63,6 \%$ & $27,3 \%$ & $9,1 \%$ \\
\hline \begin{tabular}{l} 
Уровень выраженности \\
ценностно-смыслового \\
компонента СПД по под- \\
\cline { 2 - 5 } \\
готовке плана
\end{tabular} & КГ & $68,1 \%$ & $27,3 \%$ & $4,6 \%$ \\
\hline
\end{tabular}

Как показали результаты диагностики, высокий уровень готовности оказался одинаково мало представленным у воспитателей двух детских садов.

Анализ работы педагогов по планированию деятельности с воспитанниками на неделю позволил выявить низкий уровень ориентации на определенные требования к качеству данного документа, отражающие преемственный характер развивающей деятельности с детьми по достижению возрастно-нормативных уровней развития. Вызывало затруднение осмысление принципов партнерства при создании планов - прослеживается опора на индивидуальные способы деятельности. Это выразилось в показателе, описывающем распределение ролей при подготовке к реализации планов.

При оценке операционно-технического компонента, который проявлялся в качестве текста планов, был зафиксирован низкий уровень, по мнению экспертов, у большинства педагогов. Это выражалось в несоблюдении параметров преемственности запланированных видов работы с детьми в контексте темы недели и итогового культурно-образовательного события, формулировке целей и задач не на языке развития возрастных новообразований. Было выявлено, что педагоги не всегда могут описать характерные для своей возрастной группы детей новообразования, что затрудняет постановку целей и задач планируемой с детьми образовательной деятельности.

Проведенное исследование позволило наметить стратегию сопровождения воспитателей для преодоления затруднений и формирования их готовности реализовать принципы партнерства при планировании работы с воспитанниками.

Результаты исследования положены в основание разработки модели организационно-психологических условий формирования компетенций педагогов в процессе организации ими эффективного взаимодействия при решении задач обеспечения возрастно-нормативных достижений воспитанников. Программа направлена на активизацию рефлексии ценностно-смыслового компонента деятельности воспитателей и осмысление способов взаимодействия участников при организации овладения детьми новыми видами развивающей деятельности на уровне профессионального партнерства. Данная модель может быть применена для разработки организационно-психологической программы повышения квалификации воспитателей в системе их непрерывного образования. 
Приложение 1

Критерии оценки качества продукта совместной деятельности при создании плана образовательной работы на неделю с воспитанниками

Таблица 1

\begin{tabular}{|c|c|c|c|}
\hline КРИТЕРИЙ & ПОКАЗАТЕЛЬ & ЭМПИРИЧЕСКИЕ ПРОЯВЛЕНИЯ & балл \\
\hline \multirow{3}{*}{$\begin{array}{l}\text { Формулировка целей и задач на языке опи- } \\
\text { сания динамики возрастно-нормативных } \\
\text { достижений }\end{array}$} & \multirow{3}{*}{$\begin{array}{l}\text { Наличие слов-маркеров формулировки це- } \\
\text { лей и задач на языке целевых ориентиров } \\
\text { развития детей }\end{array}$} & Присутствуют & 3 \\
\hline & & Частично присутствуют & 2 \\
\hline & & Отсутствуют & 1 \\
\hline \multirow[t]{3}{*}{$\begin{array}{l}\text { Преемственность различных видов дея- } \\
\text { тельности в течении недели }\end{array}$} & \multirow[t]{3}{*}{$\begin{array}{l}\text { Виды деятельности, запланированной с } \\
\text { детьми взаимосвязаны друг с другом }\end{array}$} & $\begin{array}{l}\text { Наличие взаимосвязи всех видов запланированных } \\
\text { занятий }\end{array}$ & 3 \\
\hline & & Частично взаимосвязаны между собой & 2 \\
\hline & & $\begin{array}{l}\text { Каждый вид деятельности обособлен, нет преемствен- } \\
\text { ности }\end{array}$ & 1 \\
\hline \multirow{3}{*}{$\begin{array}{l}\text { Соотнесение содержания запланированной } \\
\text { деятельности с темой недели }\end{array}$} & \multirow{3}{*}{$\begin{array}{l}\text { Каждый из запланированных видов дея- } \\
\text { тельности с детьми соответствует тематике } \\
\text { недели }\end{array}$} & Да & 3 \\
\hline & & Частично (не менее половины) & 2 \\
\hline & & Менее половины & 1 \\
\hline \multirow{3}{*}{$\begin{array}{l}\text { Соотнесение содержания различных ви- } \\
\text { дов деятельности с итоговым продуктом } \\
\text { недели(культурно-образовательным собы- } \\
\text { тием) }\end{array}$} & \multirow{3}{*}{$\begin{array}{l}\text { Деятельность, осуществляемая детьми } \\
\text { при выполнении данного занятия, создает } \\
\text { вклад в итоговое культурно-образователь- } \\
\text { ное событие }\end{array}$} & $\begin{array}{l}\text { Полностью - каждое занятие приносит свою пользу в } \\
\text { «копилку» КОС }\end{array}$ & 3 \\
\hline & & Частично (не менее половины) & 2 \\
\hline & & Единичные занятия соотносятся с итоговым КОС & 1 \\
\hline \multirow{6}{*}{$\begin{array}{l}\text { Соответствие форм работы возрасту воспи- } \\
\text { танников и поставленным задачам }\end{array}$} & \multirow{3}{*}{$\begin{array}{l}\text { Выбранные формы работы адекватны воз- } \\
\text { расту воспитанников }\end{array}$} & Полностью соответствуют & 3 \\
\hline & & Частично (не менее половины) & 2 \\
\hline & & Не соответствуют & 1 \\
\hline & \multirow{3}{*}{$\begin{array}{l}\text { Выбранные формы работы актуальны для } \\
\text { реализации поставленных задач и целей }\end{array}$} & Полностью соответствуют & 3 \\
\hline & & Частично (не менее половины) & 2 \\
\hline & & Не соответствуют & 1 \\
\hline
\end{tabular}

Уровень готовности к выполнению роли инструктора:

1 - низкий (0-11 баллов)

2 - средний (12-22 балла)

3 - высокий (23-33 балла)

Приложение 2

Экспертная оценка особенностей ценностно-смыслового компонента партнерской деятельности педагогов в процессе рефлексивной беседы.

Беседа с педагогами в рамках семинара по представлению планов деятельности с воспитанниками

1. Удовлетворены ли вы полученным результатом? Отвечает ли ваш план основным требованиям:

- цели и задачи сформулированы в соответствии с ориентирами развития детей данной возрастной группы;

- выдержана преемственность различных видов деятельности;

- запланированные мероприятия соотносятся с темой недели;

- запланированная деятельность соотносится с итоговым продуктом недели;

- формы работы соответствуют возрасту детей.

2. В чем проявились затруднения при достижении более качественного результата и от чего они зависели?

3. Какими мотивами вы руководствовались при составлении плана? Можете ли вы назвать вашу позицию активной? Чем, по-вашему, руководствовался партнер, опишите его позицию.

4. Как строилась работа по подготовке недельного плана деятельности с воспитанниками? Какие договоренности были созданы и как распределена совместная работа?

5. Присутствовало ли партнерство в вашей паре? В чем это выражалось?

6. Удовлетворены ли вы способами организации взаимодействия с партнером при достижении результата? 


\section{Критерии и показатели оценки ценностно-смыслового компонента готовности педагогов к осуществле- нию совместной деятельности}

Таблица 2

\begin{tabular}{|c|c|c|c|c|}
\hline КРИТЕРИЙ & \multicolumn{2}{|l|}{ ПОКАЗАТЕЛЬ } & ЭМПИРИЧЕСКИЕ ПРОЯВЛЕНИЯ & балл \\
\hline \multirow[t]{3}{*}{$\begin{array}{l}\text { Способность к рефлексии мотиваци- } \\
\text { онно-целевого компонента взаимо- } \\
\text { действия с партнером }\end{array}$} & \multirow{3}{*}{\multicolumn{2}{|c|}{$\begin{array}{l}\text { Уровень осознанности мотивационно-целевого } \\
\text { компонента СПД }\end{array}$}} & $\begin{array}{l}\text { Высокий } \\
\text { Может осознать и вербализовать: } \\
\text { - мотивы и цели осуществления } \\
\text { взаимодействия: } \\
\text { - направленность при взаимодей- } \\
\text { ствии } \\
\text { - активность }\end{array}$ & 3 \\
\hline & & & $\begin{array}{l}\text { Средний } \\
\text { Частично описывает мотивы СПД, направленность } \\
\text { при взаимодействии }\end{array}$ & 2 \\
\hline & & & $\begin{array}{l}\text { Низкий } \\
\text { Затрудняется в описании мотивов и целей совместной } \\
\text { деятельности }\end{array}$ & 1 \\
\hline \multirow{4}{*}{$\begin{array}{l}\text { Способность к вербализации и ос- } \\
\text { мыслению взаимодействия с пар- } \\
\text { тнером в СПД }\end{array}$} & \multirow[t]{2}{*}{$\begin{array}{l}\text { Уровень осознанности собственного } \\
\text { участия в совместной деятельности }\end{array}$} & Высокий & $\begin{array}{l}\text { Указывают недостатки выполнения собственных дей- } \\
\text { ствий в роли партнера }\end{array}$ & 2 \\
\hline & & Низкий & $\begin{array}{l}\text { Указывают характеристики партнера, как не владею- } \\
\text { щего способами кооперации }\end{array}$ & 1 \\
\hline & \multirow[t]{2}{*}{$\begin{array}{l}\text { Уровень осознания взаимодействия } \\
\text { как совместной деятельности }\end{array}$} & Высокий & $\begin{array}{l}\text { Указывают недостатки совместной договоренности } 0 \\
\text { плане деятельности }\end{array}$ & 2 \\
\hline & & Низкий & $\begin{array}{l}\text { Не указывают недостатки совместной договоренности } \\
\text { о плане деятельности }\end{array}$ & 1 \\
\hline \multirow[t]{3}{*}{$\begin{array}{l}\text { Способность к вербализации каче- } \\
\text { ственного взаимодействия }\end{array}$} & \multirow[t]{3}{*}{$\begin{array}{l}\text { Уровень вербализации качественно- } \\
\text { го взаимодействия }\end{array}$} & Высокий & $\begin{array}{l}\text { Описывают качества слаженной кооперации, характе- } \\
\text { ризуют ее результат и описывают компоненты комму- } \\
\text { никации, которая привела к этому }\end{array}$ & 3 \\
\hline & & Средний & $\begin{array}{l}\text { Указывается необходимость ориентироваться на пар- } \\
\text { тнера при выполнении кооперации, потребность во } \\
\text { владении способами коммуникации }\end{array}$ & 2 \\
\hline & & Низкий & $\begin{array}{l}\text { Не дают ответа на вопросы, затрудняются в подборе } \\
\text { слов и выражений }\end{array}$ & 1 \\
\hline \multirow[t]{3}{*}{$\begin{array}{l}\text { Способность оценить качество про- } \\
\text { дукта совместной деятельности с } \\
\text { позиции эксперта }\end{array}$} & \multirow[t]{3}{*}{$\begin{array}{l}\text { Уровень качества оценки созданных } \\
\text { продуктов, ее объективность, спо- } \\
\text { собность осмыслить эталон качества } \\
\text { и соотнести с ним готовый продукт }\end{array}$} & Высокий & $\begin{array}{l}\text { Осмысливают в качестве эталона планирования доку- } \\
\text { мент, обладающий комплексными характеристиками } \\
\text { (т.е. соблюден весь перечень требований к плану). } \\
\text { При соотнесении собственных продуктов объективно } \\
\text { отмечают успешные и несоответствующие черты соб- } \\
\text { ственного плана. }\end{array}$ & 3 \\
\hline & & Средний & $\begin{array}{l}\text { При определении эталона не учитывают весь спектр } \\
\text { требований. Соотнося собственный продукт с этало- } \\
\text { ном частично отмечают удавшиеся и несоответству- } \\
\text { ющие черты. }\end{array}$ & 2 \\
\hline & & Низкий & $\begin{array}{l}\text { Вызывает затруднение определение эталона планиро- } \\
\text { вания. При анализе собственного продукта затрудня- } \\
\text { ются в соотнесении с требованиями, отметке качеств } \\
\text { плана. }\end{array}$ & 1 \\
\hline
\end{tabular}

Уровень сформированности мотивационно-целевого и ценностно-смыслового компонента взаимодействия в совместной деятельности:

1 - низкий (0-8 баллов)

2 - средний (9-16 баллов)

3 - высокий (17-24 балла) 


\section{ЛИТЕРАТУРА}

1. Балабанова Н.В. Образовательная среда школы и проблемы социализации личности: Монография. — Краснодар, 2002.

2. Беляев Г.Ю. Формирование термина «образовательная среда» в психолого-педагогической литературе конца XX - начала XXI века (0бразовательная среда как предмет профессиональной деятельности педагога-воспитателя). -URL: http://dzd.rksmb.org/science/bel06.htm.

3. Григорьева М.В. Понятие «образовательная среда» и модели образовательных сред в современной отечественной педагогической психологии // Ученые записки. - 2010. Т. 3. Сер. Психология. Педагогика. № 4 (12) - с. 3-11

4. Леонтьев Д.А. Психология смысла. Природа, строение и динамика смысловой реальности. М.: Смысл, 2007. 511 с.

5. Ляудис, В.Я. Структура продуктивного учебного взаимодействия -[Электронный ресурс / В.Я. Ляудис/ - Электрон. дан. - [Б. м.], [2007]. Режим доступа: http://www.ido.rudn.ru/psychology/pedagogical_psychology/ch8_4.html

6. Образовательная среда школы как фактор психического развития учащихся / под ред. В.В. Рубцова, Н.И. Поливановой. - Москва- Обнинск: ИГ-СОЦИН, 2007. $-288 \mathrm{c}$.

7. Панов, В.И. Психодидактика образовательных систем: теория и практика. - СПб.: Питер, 2007. — 352 с.

8. Поливанова К.Н., Ермакова И.В. Образовательная среда урока: психологическая характеристика // 2-я Российская конференция по экологической психологии: Тезисы. (Москва, 12-14 апреля 2000 года).- М., 2000. - С. 205-207.

9. Рубцов В.В. Оценка образовательной среды школы // 2-я Российская конференция по экологической психологии. Тезисы. (Москва, 12-14 апреля 2000 года). - М., 2000. - С. 176-177.

10. Слободчиков В.И. Образовательная среда: реализация целей образования в пространстве культуры // Новые ценности образования: культурные модели школ. - М., 1997. - Вып. №2 7.

11. Слободчиков В.И. 0 понятии образовательной среды в концепции развивающего образования // 2-я Российская конференция по экологической психологии. Тезисы. (Москва, 12-14 апреля 2000 года) - М., 2000. - С. 172-176.

12. Приказ Министерства образования и науки РФ от 17 октября 2013 г. № 1155 «0б утверждении федерального государственного образовательного стандарта дошкольного образования»

13. Цукерман, Г.А. Взаимодействие ребенка и взрослого, творящее зону ближайшего развития [Текст]. — / Г.А. Цукерман // Культурно-историческая психология, - 2006. № 4. С. 61-73

14. Шибаева Л.В. Становление учащегося как субъекта образования в условиях развивающего обучения/ Л.В. Шибаева — Сургут, 2010. — 267с.

15. Щербакова Т.Н. К вопросу о структуре образовательной среды учебных учреждений // Молодой ученый. — 2012. — №5. — C. 545-548. — URL https:// moluch.ru/archive/40/4867/ (дата обращения: 24.01.2020).

16. Ясвин В.А. Образовательная среда: от моделирования к проектированию. - М.: Смысл, 2001. - 365 с.

(c) Шибаева Людмила Васильевна (shibaeva2003@gmail.com), Собакинских Оксана Владимировна (mixvel@yandex.ru).

Журнал «Современная наука: актуальные проблемы теории и практики»

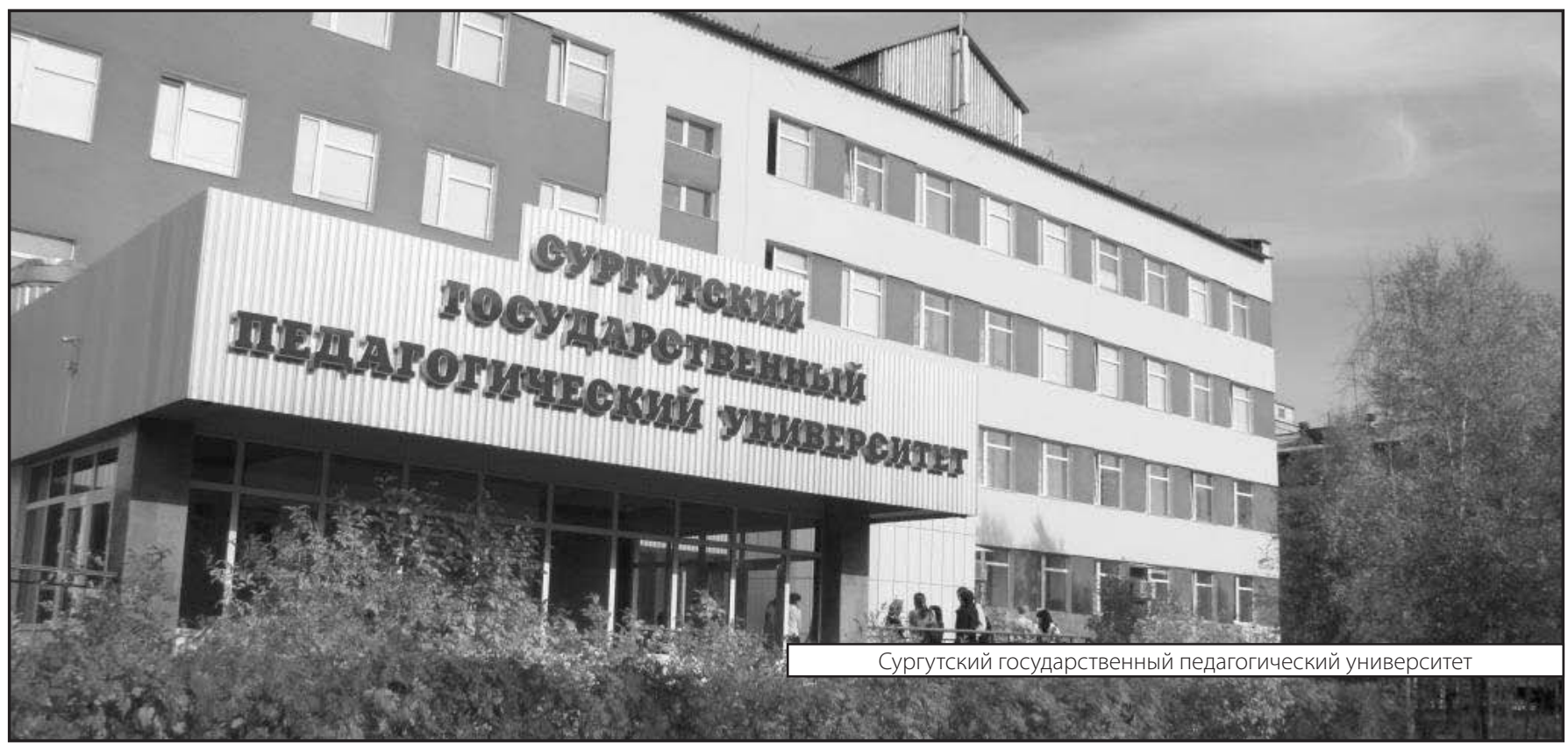

